\title{
Financial Dependence and Economic Growth in Spain
}

\author{
Lamothe, P. \\ Universidad Autónoma de Madrid, Madrid, Spain \\ Fernández, M. A., Ríos, M. \\ Universidad de Málaga, Málaga, Spain
}

\begin{abstract}
The authors intend to contribute in this paper towards a debate on the consequences of external financing needs of small and medium enterprises (SMEs) regarding its economic growth. The authors' research differs for using like proxy of external financing dependence of SMEs the flows of investments that cannot be financed with generated cash flows. The results thus obtained show that financial dependence accounts for economic growth of SMEs, and that there are other variables of control of significance such as those of financial development. The authors present evidence on better soundness achievement about conclusions pertaining to SMEs if they obtained results emerge from independent sub-sectors in SMEs, especially in those countries with a higher percentage of small-sized companies, which do not answer in the same way to the considered model.
\end{abstract}

Keywords: small and medium enterprises (SMEs), economic growth, financial development, Spain

\section{Introduction}

This paper studies the relationship between the economic growth of companies and the use of external financing that the same companies do. Current research indicates that the bigger the efficiency in the process of intermediation (financial development), the lower the costs of such intermediation and, consequently, the higher the economic growth. Furthermore, it considers the use of external financing helps increase the efficiency in capital allocation, to the effect that the above mentioned external financing goes towards the most profitable businesses.

Our aim in this paper is to contribute to the debate on the consequences of external financing of SMEs and to the efficiency regarding capital allocation, by especially analyzing the above mentioned consequences on the industrial sector of SMEs.

In order to achieve it, the authors are going to develop a model here to by which the external financing of a sector ought to have a consequence on the effectiveness of its capital allocation; that is to say, the bigger a company needs external financing, the more it has a more efficient capital allocation. Concerning the industrial

Lamothe, P., Professor, Departamento de Financiación e Investigación Comercial, Universidad Autónoma de Madrid.

Fernández, M. A., Lecturer, Departamento de Finanzas y Contabilidad, Universidad de Málaga.

Ríos, M., Lecturer, Departamento de Finanzas y Contabilidad, Universidad de Málaga.

Correspondence concerning this article should be addressed to Ríos, M., Departamento de Finanzas y Contabilidad, Universidad de Málaga, 29071, Spain. E-mail: mtrios@uma.es. 
Spanish sector of SMEs, the authors present new evidence of the relationship between company growth and the level of external financing dependence, which uses the proposed measure by Rajan and Zingales (1998).

The authors will demonstrate that external financing needs are positively related to the efficiency in capital allocation, even after being controlled by the use of variables in the financial development.

The model we propose helps to improve previous ones, which dealt with the consequences of having financial market operations restricted and capital allocation efficiency (Levine, 1991; Bencivenga, Smith, \& Starr, 1995; Almeida \& Wolfenson, 2005; Beck, Demirgüç-Kunt, Laeven, \& Levine, 2008). It is in this context that our analysis differs for using like proxy of external financing dependence of SMEs the flows of investments that cannot be financed with generated cash flows, in the wake of Rajan and Zingales's (1998) proposed original measure of dependence. Therefore, the model presented hereby is not the first one that tries to examine the consequences of external financing in (economic) growth. Both Rajan and Zingales (1998) and Maudos and Fernández (2006) also used this relationship among variables but they failed to focus on the detailed analysis of the relation between investments/generated cash flow in SMEs. The results show that, in Spain, and regarding external financing needs and capital allocation, the analysis of this evidence may be of interest to certain industrial sectors and to middle-sized companies.

The paper comprises of the following parts: in part two, there is an evaluation on the specialized existing literature. In part three, there is a development of the applied methodology. In part four, data used is produced, and in part five, the results obtained are exhibited. Lastly, the main conclusions arrived at are presented in part six.

\section{Literature Review}

Current research suggests that capital allocation efficiency depends, inter alia, on variables such as external financing needs of SMEs (Almeda \& Wolfeson, 2005). Likewise, there have already been several empirical studies to relate economic growth to financial development (Rajan \& Zigales, 1998; Levine, Loayza, \& Beck, 2000; Beck et al., 2008).

Some other studies put emphasis on the role played by banks within the system (Gershenkron, 1962) and the importance given to government policies relative to financial development and economic growth (Demirgüç-Kunt \& Levine, 2008). There are also other pundits who put emphasis on market advantages over banks, as far as capital allocation is concerned (Allen, 1993). Even the main proxy for the financial system seems to be the defense of the efficiency of the legal system to protect external investors (La Porta, López de Silanes, Shleifer, \& Vishny, 1998). It is shown that when a legal system of protection to any country's investors is not too low, financial resources released during the liquidation of companies, which has been induced by external investors, will find their own way for more productive activities (Almeida \& Wolfenson, 2005). Likewise, Wurgler (2000) found evidence that measures taken to help develop financial development and protect the external investor, were positively related to the efficiency in capital allocation. Along the same lines, there are the studies of Levine (1991), Bencivenga et al. (1995), and Shleifer and Wolfenzon (2002).

Considering the environment of SMEs, current research has not yet resolved how to distribute the effects of financial development between economic growths (Demirgüç-Kunt \& Levine, 2008). The works of Galor and Zeira (1993), and of Cestone and White (2003) hold that frictions due to costs of transactions and asymmetric 
information were corrected by the development of the financial system proper, which has a positive impact on SMEs. It is also held in these works that an increase in the property rights of the investors helps increase external financing in SMEs, a lot more than in big-sized companies (Beck et al., 2004).

Irrespective of the foregoing, another line of research brings about different results that hold the view that the greatest costs of transaction supported by SMEs make big-sized companies increase their volume and have a certain edge over the former (Greenwood \& Jovanovic, 1990; Haber, Razo, \& Maurer, 2003).

So, external financing needs can get a better capital allocation, even in those circumstances in which lack of efficiency is being introduced at the level of the business, a fact that will provoke, in the same manner, excessive growth. External investors would rather terminate slack projects since just a small part of future returns can be obtained out of them. Yet, in the absence of external financing, the said investors prefer not to terminate such projects because the referenced projects keep returns in its entirety. Thus, it would seem logical that companies in need of an increase in external financing will be wound up more often than those that are self-financed. Whereas complete liquidation might look most appropriate to an isolated company, it could as well be socially beneficial because of the financing released out of slack projects to highly productive projects, improving capital allocation in this way (Diamond, 1991).

As the authors have mentioned, those models that relate external financing dependence of companies to economic growth, tend to consider that an increase in said dependence would lead to betterment in capital allocation (Goldsmith, 1969; Levine \& Zervos, 1998; Shleifer \& Wolfenzon, 2002; Demirgüç-Kunt \& Levine, 2008). Almeida and Wolfenzon (2005) explained how such relations of dependence correlate with each other through the possibility that companies with a low-productivity rate should tend to liquidate its projects. This is, precisely, the role that external financing is playing at the outset. If financial needs requirements are high enough, the only way a business can pay investors is by means of some liquidation at the cited initial stage. Accordingly, it is thought to be less expensive to decide to liquidate a project when its productivity is low than high. If the liquidation is necessary for the initial financing, the perfect contract will involve the liquidation of those projects of low-productivity in the first place. According to this theory, the behaviour of market reassignment at the initial stage means that the existence of balance between supply and demand of funds is not guaranteed. In the supply-side, there is a totality of $K+T_{a}$ resources to be allocated, being $K$ the total spare capital for market and $T_{a}$ the capital of the projects liquidated at this initial stage. This quantity is determined by the contract that businessmen register previously. To put it in other words, that is:

$$
T_{a}=\int_{j \in C} d j
$$

where $C$ is the number of projects running and $j$ identifies every investor. Thus, for a distribution $r^{j}$ on the capital market, the balance has to agree with both the maximization of the investor and satisfy the condition of market offset:

$$
\omega+\int_{j \in C} r^{j} d j=K+T
$$

where $\omega$ is the number of resources allocated to technology in general.

In short, parts of the capital allocated to projects liquidated are now geared towards high-productivity projects, considerably improving the total sum. External investors demand liquidation for being this the only way 
of recovering their investments. Although this compulsory liquidation is, from an isolated business point of view, clearly inefficient, yet it is beneficial for the company's economy in its entirety since the additional funds supplied to external market will be in the hands of better users (Diamond, 1991).

To illustrate the main mechanism of their model, Almeida and Wolfenzon (2005) used a similar expression to the one shown in Figure 1. At an initial stage, (a), the return in the market, $x^{*}$, is:

$$
x^{*}=x\left(K+T_{a}\right)
$$

Being $K$ the spare capital, and $T_{a}$ the low-productivity liquidated projects' global collection of this period. In this case, even if high-productivity companies are the best users of the said capital, they cannot attract any capital because market yield is higher than the highest yield they can provide, $Y_{H}$, that is to say:

$$
x^{*}>Y_{H}
$$

Then, bearing in mind that businesses of high productivity do not attract new capitals any longer, it would also be most appropriate, from a social perspective, to liquidate medium-to-poor productivity projects while providing their capital to projects of high productivity. However, this reassignment does not happen voluntarily. Businesses with projects of medium productivity generate cash flows of $Y_{H}$ if they continue. If these projects are liquidated and the recovered unit is invested in the market, they receive the quantity $x^{*}$ of the expression (3). But if one corroborates that:

$$
x\left(K+T_{a}\right)<Y_{H}
$$

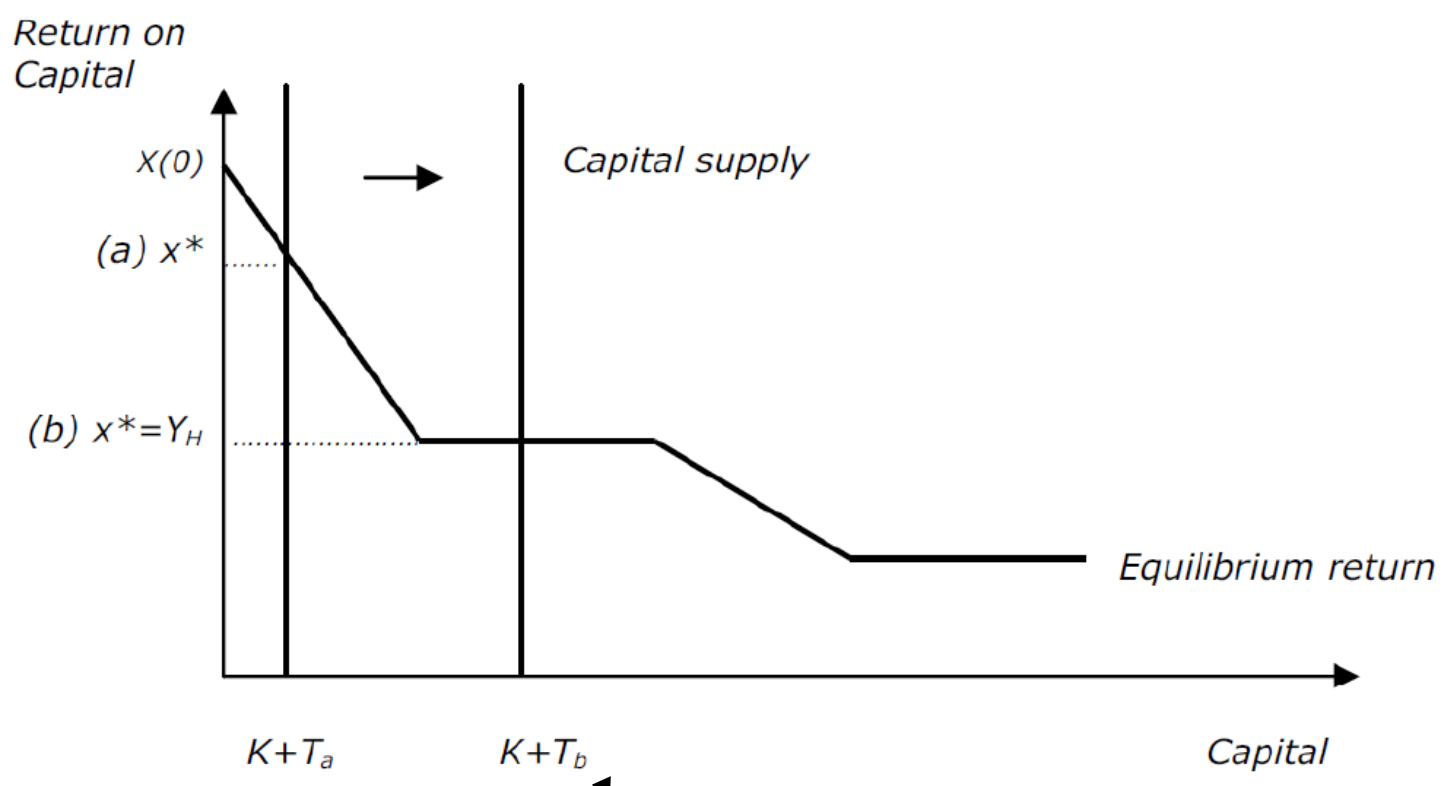

Figure 1. Equilibrium return as a function of capital supply.

Then companies with projects of medium productivity will not be liquidated, but they will continue. In conformity with the foregoing, capital allocation is misrepresented for two reasons, that is to say, high-productivity companies cannot attract the capital that is available for assignment, and projects with medium productivity choose not to liquidate and, instead, allocate their capital to those companies of high productivity. The balance at a later time, represented for (b) in Figure 1, reflects the process when liquidation is necessary for financing, and the new balance in the assignment of resources will demand that these projects of medium productivity be liquidated. That is why the new capital supply, $K+T_{b}$ is greater that in (a): 


$$
K+T_{b}>K+T_{a}
$$

In this case, the additional capital takes a bearish market performance in order that high productivity companies could attract resources. In other words, certain capital of the liquidated projects finds its way towards high productivity projects, potentially improving the total benefit.

\section{Methodology}

In this paper, the authors propose to confirm the hypothesis which states that external financing needs of the Spanish industry helps to increase the efficiency in capital allocation in SMEs. This is tantamount to considering the results of financial development on economic growth alike.

Measurement of the level of dependence of the external financing of all analyzed companies relies, however, on considering the existence of a specific environment, such as financial, developed, and qualified markets, where companies should not meet constraints on the access to financing.

The choice of a developed country for the analysis is a way of avoiding the issue of distinguishing between supply and demand of financing, since the higher level of financial development a country has, the less friction of access to financing will be (Rajan \& Zingales, 1998; Maudos \& Fernández, 2006).

In this regard, we believe that external financing needs have an exogenous component. Previous literature on this issue has argued that, due to technological reasons, the need of external financing to the level of industry would be, up to a certain point, exogenous and might be measured by the current use of external financing on a fairly well developed capital market (Rajan \& Zingales, 1998).

This first hypothesis supposes executing the regression of the amount of economic growth, that is to say, comparison between the increase in sales and the internal rate of return of every company, in need of external financing and controls, in the wake of border and Zingales's (1998) proposal. The distinction builds on ascertaining whether the companies most dependent on external financing can experience high rates of growth, once certain features of financial development of every unit are under control. Consequently, the model follows as:

$$
\text { Growth }_{i, t}=\text { Constant }+\beta_{1} \text { Financial dependence }_{1, t}+\beta_{2} \text { Financial development }_{1, t}+\varepsilon_{1, t}
$$

where Growth is a dummy variable that takes the value of 1 when the company $i$ increases its sales more than expected, due to the internal rate return (excess of growth) during the $j$ period, and takes the value 0 otherwise; Financial dependence is the independent variable measured from the flow of investments carried out by the company that cannot be financed by the generated cash-flow (Rajan \& Zingales, 1998); Financial development represents a group of variables of control on the relative volume that every company generates and on its assets profitability. It brings us closer to the degree of efficiency accomplished by companies at a financial level, in a similar way to Almeida and Wolfenzon's (2005) proposal in respect of financial intermediaries. Lastly $\beta$ is the coefficient and $\varepsilon$ the error term.

Our work, in addition, considers dimension so as to identify the specific effect on SMEs; accordingly, we include a new independent variable, Size, which refers to the number of contracted workers. A dummy variable shows it in the model and takes the value 0 when the level of employment is fewer than 50 workers (small 
enterprise), and 1 when the number of workers is in the range of 50 to 250 (medium-sized enterprise) ${ }^{1}$. Thus the model is as following:

Growth $_{i, t}=$ Constant $+\beta_{1}$ Financial dependence $_{1, t}+\beta_{2}$ Financial development $_{1, t}+\beta_{3}$ Size dummy $_{1, t}+\varepsilon_{1, t}$

Continuing this methodological trend, regression in our case is of a logistic binomial type and consists of obtaining a linear function of the independent variables, so that it allows to systematizing the SMEs of the sample under one of two groups of the population, according to the growth of the same ones.

Coefficients of the independent variables are obtained by models of conditional probability through a dependent dichotomous variable. The model of logistic regression is based on the quotient of possibilities that represent the probability of a success as compared with the probability of a failure. The quotient of possibilities is formulated as follows:

$$
P(E) /(1-P(E))
$$

where $P(E)$ is the probability of success. In addition, the logit model can be formulated as a linear function of different and independent variables, with the formula:

$$
\log \{P(E) /(1-P(E))\}=\beta_{0}+\beta_{1} X_{1}+\ldots+\beta_{n} X_{n}
$$

where $\beta_{0}$ is the coefficient of interception of the function; $\beta_{1}, \beta_{2}, \beta_{3}$ and so on are the coefficients of the independent variables (the regression coefficients), and $x_{1}, x_{2}, x_{3}$ respectively are the values of such variables of control.

In the model, the estimated values of the dependent variable can be interpreted as prediction of the probability of a favorable event, with values between 0 and 1 . In this work, the estimated value of the dependent dichotomous variable is interpreted as prediction of the probability of which a company should have had growth in the period of study $P(E)$. Thus, calculating the value of $P(E)$ in the expression (10), prediction of probability of growth is defined like:

$$
P(E)=e^{y} /\left(1+e^{y}\right)
$$

where: $\left\{\begin{array}{l}e=\text { the base of natural logarithm } \\ y=\beta_{0}+\beta_{1} X_{1}+\ldots+\beta_{n} X_{n}\end{array}\right.$

The classification of the companies of the sample into the so called groups of "growth" and "without growth" is determined by the logit value $(y)$ of the model described in expression (11), which establishes that companies with $P(E)$ equal or lower than 0.5 should pertain to the group of companies "without growth". When the values are higher than 0.5 they are classified under the companies group of "growth".

With the values obtained from the logistic regression method, it is possible to know, on the hand, the average probability of attaining growth both on the part of a SME that possesses certain structural characteristics and a group of SMEs that has certain types of factors in common; and on the other hand, the logistic calculations will allow us to observe the group of variables that act with a greater intensity.

In addition to the foregoing, the authors also propose a statistical exploratory study of the available data on the variables to achieve a first approach to the issue. It is a question of verifying, then, the expected performance and the homoscedasticity of the variables, of observing the averages and the anomalies of data, of detecting outliers and filtering of the same ones. As customary in exploratory techniques, the authors have obtained

\footnotetext{
${ }^{1}$ Commission Recommendation 2003/361/EC of 6.05.2003 concerning the definition of micro, small and medium-sized enterprises (Official Journal L 124 of 20.05.2003).
} 
different measures of central trend (mean, median), of dispersion (variance, standard deviation, and range), of skewness and kurtosis (Fisher's coefficients) and position (quantiles and Tukey's box plot). Likewise, expected performance has been verified both in Kolmogorov-Smirnov's test for a sample and Shapiro-Wilk’s test.

\section{Data}

In this section, the authors will summarize the implications of our model, by comparing them with the empirical available evidence and presenting new contributions in the financial behaviour of SMEs.

This work is characterized for being a pioneering study in providing results of SMEs, in accordance with Rajan and Zingales's (1998) original model; that is to say, by presenting a measure of financial dependence of SMEs arising from the flows of investments that cannot be financed by means of generated cash flows.

To determine the main explanatory variables of economic growth of the SMEs, the authors have used the financial information of a sample of 329 industrial Spanish companies for the period 2001 to 2008, which gives place to the utilization of 2,632 available observations. The information comes from Bureau Van Dijk Electronic Publishing's comparable financial databases AMADEUS and SABI, which contain financial information of more than seven million European companies. The SMEs were selected in accordance with the NCEA Rev.1.1. and NCEA-2009 classifications by means of a random stratified sampling, which will allow to infer the population results with a $95 \%$ confidence and a sampling error below $2 \%$.

The work has consisted of establishing the existing relation between the growth of the different businesses of the sample and the financial dependence of the same, while also obtaining information on the coefficients, on the goodness-of-fit test, on the individual and group significance which will show shortly.

Table 1

\section{Financial, Size and Dependence Variables}

No. of businesses: 329

No. of observations: 2,632

Period of time: 2001-2008

SME Criteria: Turnover $<50 €$ million of and Employment $<250$ workers; ACT is the amount of the total assets of the statement of financial position; EMP is the level of employment during the period; INV measures the increase in investment during the period of study; CFG is the generated cash-flow; DFE is the variable of external financial dependence of the company, and ROA is the profitability on assets.

INV, CFG, and DFE in $10^{3} €$.

\begin{tabular}{|c|c|c|c|c|c|c|}
\hline Variables & Units & Mean & Median & S.D. & Max. & Min. \\
\hline \multicolumn{7}{|c|}{ Descriptive terms: } \\
\hline $\mathrm{ACT}$ & $10^{3} €$ & $4,682.25$ & 675.77 & $11,082.52$ & $149,011.19$ & 4.27 \\
\hline EMP & No. of workers & 24.33 & 9.00 & 40.21 & 248.00 & 1.00 \\
\hline ROA & Return on assets (\%) & 5.08 & 4.85 & 10.77 & 116.13 & -113.63 \\
\hline \multicolumn{7}{|c|}{ Calculation of financial dependence: } \\
\hline INV & (Asset $_{j}-$ Asset $\left._{j-1}\right)$ & 420.19 & 20.92 & $2,674.11$ & $62,191.79$ & $-29,143.88$ \\
\hline CFG & (Net profit + amortizations) & 340.10 & 45.92 & $1,088.64$ & $16,608.06$ & $-9,477.39$ \\
\hline DFE & $(\mathrm{INV}-\mathrm{CFG})$ & 80.09 & -11.17 & $2,459.37$ & $54,736.79$ & $-34,694.06$ \\
\hline
\end{tabular}

In an exploratory previous analysis, as it appears in Table 1, the authors verify the characteristics of the key variables of the study. For the period from 2001 to 2008, the sample offers an average volume of assets (ACT) of $4.5 €$ million and an average level of employment (EMP) of 24 workers, reflecting the SME's nature of the sample, 
and even, the profile of micro or small-sized enterprise that industrial Spanish population has. On the other hand, the Return on Assets (ROA) indicator achieves an average of 5.08\%.

Table 1 also shows the results of the financial dependence calculation of the sample, using to facilitate its implementation, thus, a comparison between the growth of investments and the cash-flow generated in the period. One can verify, consequently, an average annual investment (INV) of 420,190€ and generated resources (CFG) rising to 340,100€, what has provoked that the average financial dependence be positive in 80,090€, and has acknowledged that external financing needs (DFE) for said amount occur.

\section{Empirical Results}

Table 2 shows the results of the logistic regression method carried out which refers to the relationship between economic growth and the independent variables selected. The results achieved indicate that financial dependence accounts for the level of growth of SMEs and that also other variables of control are significant, such as those of financial development and size.

The value of the statistical Chi-square is in use for the contrast of the global significance of the model, whose test confirms the void hypothesis that says all coefficients of the equation, except the constant, are void. The results of this test allow us to reject the void hypothesis and admit the model as valid.

To assess the suitability of the model, the authors compare the number of cases observed with those predicted by the estimated model. In our case, the predictive capacity of the model, measured by the percentage of successes is $66.80 \%$, taking 0.5 as a cut-off point.

In the model, the coefficient estimated associated with the explanatory variable Financial Dependence is of significance and positive to $1 \%$, by which one can infer a strong relation between the levels of growth and financial dependence. This conclusion is in line with both Rajan and Zingales's (1998) and Almeida and Wolfenson's (2005) works. Likewise, the Financial Development variable also exercises a considerable influence in the growth of SMEs, and one can notice in Table 2 that the coefficient linked to this variable is significant to $1 \%$ with a positive sign, showing that they are also in direct relation with the growth of SMEs, in conformity with the results obtained by both Levine and Zervos (1998) and Shleifer and Wolfenzon (2002). Finally, and regarding the Size variable, results clearly show that this variable turns out to be statistically significant at a 5\% level, and with a negative sign in its coefficient, confirming the reverse effect of the dimension of a SME in its growth.

Checking the influence that dimension has, that is to say, that the smallest companies are those that achieve greater growth, suggests us the possibility of obtaining better robustness of the model, if we analyze the sensitivity of the results with two new contrasts: (a) Excluding from the sampling companies of a significant dimension (ME) and taking only those whose average level of employment is lower than 50 workers, thus fulfilling the criterion of small enterprises, regarding the Commission Recommendation 2003/361/EC concerning the definition of micro, small and medium-sized enterprises (SMEs); and (b) The incorporation of $\mathrm{ME}$ and the exclusion of SE. The contrasts are realized taking equality (2) basically as an analytical reference. Under Table 3, results of previous propositions are to be found. If we compare predictive capacity, the new contrasts seem to be suitable, especially in the segment of ME, where correct predictions are of $80 \%$. However, in the segment of SE, predictions only account for $65 \%$ of the cases. 
Table 2

Growth and Financial Dependence in SMEs

Table 2 shows the results of the logistic regression, taking Growth as a dependent variable. The estimated model is:

Growth $_{i, t}=$ Constant $+\beta_{1}$ Financial dependence $_{1, t}+\beta_{2}$ Financial development $_{1, t}$

$$
+\beta_{3} \text { Size dummy } 1, t+\varepsilon_{1, t}
$$

Growth is a dummy variable that takes the value 1 when the business $i$ grows in sales more than expected, due to the internal rate return during the $j$ period and takes the value 0 otherwise; Financial dependence is the independent variable, measured from the flow of investments, that cannot be financed by the generated cash-flow; Financial Development represents a variable of control that brings near the degree of efficiency achieved by the financial intermediation through the generated cash-flows; Size is controlling the volume through the level of employment, taking the value 0 when the SME has fewer than 50 workers and 1 otherwise; $\beta$ is the coefficient; and $\varepsilon$ is the error term.

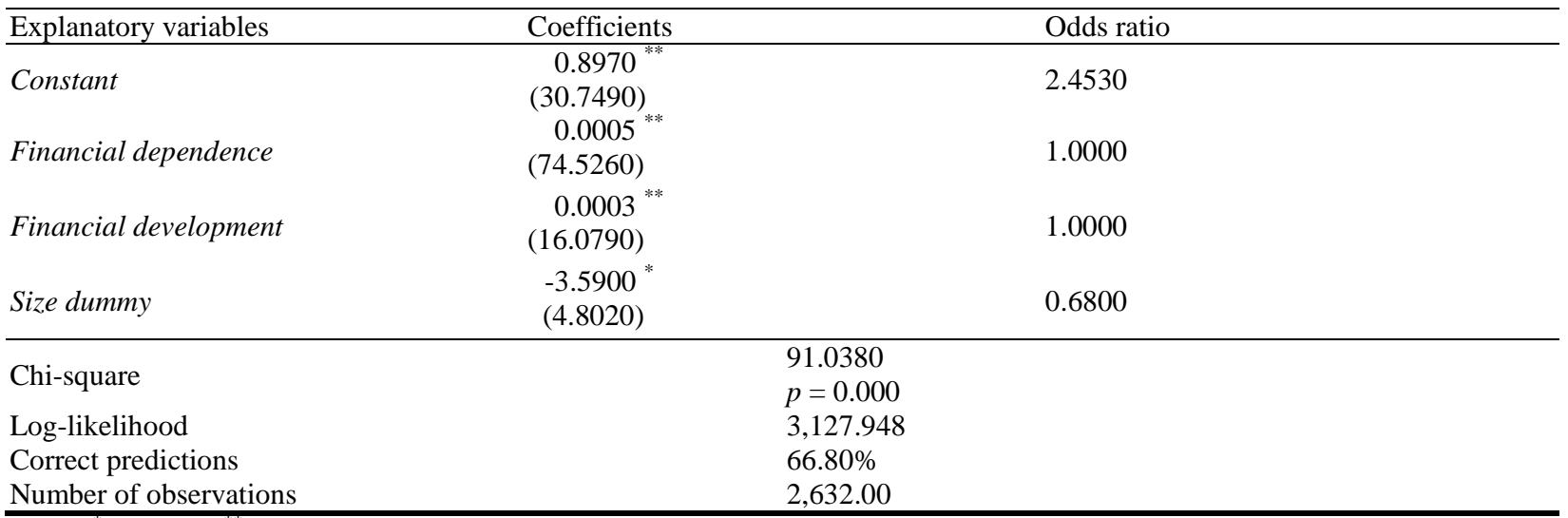

Notes. ${ }^{*} p<0.05,{ }^{* *} p<0.001$; Statistical “ $t$ ” between brackets; Estimations based on maximum likelihood.

Table 3

\section{Growth, Financial Dependence and Size of SMEs}

Model (1) shows the results of the logistic regression applied to businesses of the sample qualified like SE (Micro and Small Enterprise): Criterion employment $<50$ workers; model (2) shows the results of the regression applied to the businesses qualified like ME (Medium Enterprise). Criterion: $50<$ workers $<250$

Relationship between growth and the explanatory variables is estimated through the model:

$$
\text { Growth }_{i, t}=\text { Constant }+\beta_{1} \text { Financial Dependence }_{1, t}+\beta_{2} \text { Financial Development }_{1, t}+\varepsilon_{1, t}
$$

Growth is a dummy variable that takes the value 1 when the business $i$ grows in sales more than expected, due to the internal rate return during the $j$ period, and takes the value 0 otherwise; Financial dependence is the independent variable, measured from the flow of investments, that cannot be financed by the generated cash-flow; Financial Development represents a variable of control that brings near the degree of efficiency achieved by the financial intermediation through the generated cash-flows, $\beta$ is the coefficient and $\varepsilon$ is the error term.

(1)

\begin{tabular}{lc}
\hline Explanatory variables & Coefficient \\
Constant & $0.5200^{* *}$ \\
& $(119.6080)^{* *}$ \\
Financial Dependence & $0.0086^{* *}$ \\
& $(49.3580)^{* *}$ \\
Financial Development & $0.0056^{* *}$ \\
& $(15.7020)$ \\
\hline
\end{tabular}

Chi-square

Log-likelihood

Correct predictions

Number of observations
(2)

Odds ratio

2.5420

1.0000

1.0000

\begin{tabular}{ll}
81.908 & 16.320 \\
$p=0.000$ & $p=0.038$ \\
2776.374 & 343.446 \\
$65.00 \%$ & $80.00 \%$ \\
$2,196.00$ & 344.00 \\
\hline
\end{tabular}

Notes. * $p<0.05,{ }^{* * *} p<0.001$; “Statistical” between brackets; Estimations based on maximum likelihood. 
The positive relationship between external financing needs and Levine and Loayza's (2000) measure of economic growth remains after controlling the financial development of the SMEs. Yet, this relationship strongly emerges for the segment of medium-sized enterprises (ME), as a fact which confirms the importance of the dimension, even inside the group of Spanish SMEs, with a great percentage of micro-enterprises which do not answer in the same way to the considered model.

\section{Conclusions}

In this work, the authors have used the financial information of a sample of industrial Spanish SMEs corresponding to the period from 2001 to 2008 to obtain empirical evidence on the impact of external financing needs in the economic growth.

The authors have verified that external financing needs increase the measure of companies' growth and that this growth is also influenced by financial managerial development. Both variables of control have turned out to be of significance and with direct relation on the growth of the SMEs, although it could be required a deeper analysis to determine firmly this conclusion. As a case in point, one can observe the importance that dimension has inside the group of Spanish SMEs, with a higher percentage of truly small-sized companies, which do not answer in the same way to the considered model, and for whom a greater dependence of external financing has a less immediate impact than in those medium-sized experienced companies.

Furthermore, we believe that the mechanism described in this work can help to explain the levels of development of SMEs and differences with reference to big-sized companies.

The results on the dimension inside the SMEs sampling have been significant, allowing us to obtain a better prediction of the model by means of analyzing the reliability of such results with two new contrasts, one focused exclusively on small-sized enterprises, and the other only on medium-sized enterprises.

In fact, the positive outcome of external financing needs on a company's growth reveals itself stronger in companies of standard dimension, which alert us that in countries with SMEs characterized by a remarkably small dimension, like in Spain's case, external financing can influence capital allocation efficiency through other mechanisms. Therefore, exploring alternative data, which will enable control with variables capable of detecting restrictions to the financing of small-sized companies, might be of interest.

\section{References}

Allen, F. (1993). Stock markets and resource allocation. In C. Mayer, \& X. Vives (Eds.), Capital Markets and Financial Intermediation (pp. 81-107). Cambridge: Cambridge University Press.

Almeida, H., \& Wolfenzon, D. (2005). The effect of external finance on the equilibrium allocation of capital. Journal of Finance Economic, 75, 133-164.

Beck, T., Demirgüç-Kunt, A., \& Maksimovic, V. (2004). Financing patterns around the world: Are small firms different? Journal of Finance Economic, 89(3), 467-487.

Beck, T., Demirgüç-Kunt, A., Laeven, L., \& Levine, R. (2008). Finance, firm size and growth. Journal of Money, Credit and Banking, 7(40), 1379-1405.

Bencivenga, V. R., Smith, B. D., \& Starr, R. M. (1995). Equity markets, transaction costs, and capital accumulation. Policy Research Working Paper Series, 1456. The World Bank.

Cestone, G., \& White, L. (2003). Anticompetitive contracting: The design of financial claims. The Journal of Finance, 58(5), 2109-2142.

Demirgüç-Kunt, A., \& Levine, R. (2008). Finance, financial sector policies and long-run growth. Policy Research Working Paper, 
4469. The World Bank.

Diamond, D. W. (1991). Debt maturity structure and liquidity risk. Quarterly Journal of Economics, 106, 709-737.

Galor, O. \& Zeira, J. (1993). Income distribution and macroeconomics. Review of Economic Studies, 60, 35-52.

Gershenkron, A. (1962). Economic backwardness in historical perspective. A book of essays. Cambridge: Harvard University Press.

Goldsmith, R. W. (1969). Financial structure and development. New Haven and London: Yale University Press.

Greenwood, J., \& Jovanovic, B. (1990). Financial development, growth, and the distribution of income. Journal of Political Economic, 98, 1076-1107.

Haber, S. H., Razo, A., \& Maurer, N. (2003). The politics of property rights: Political instability, credible commitments, and economic growth in Mexico. Cambridge: Cambridge University Press.

La Porta, R., López de Silanes, F., Shleifer, A., \& Vishny, R. (1998). Law and finance. Journal of Political Economy, 106, 1113-1155.

Levine, R. (1991). Stock markets, growth and tax policy. Journal of Finance, 46, 1145-1165.

Levine, R., \& Zevros, S. (1998). Stock markets, banks, and economic growth. American Economic Review, 88, 537-558.

Levine, R., Loayza, N., \& Beck, T. (2000). Financial intermediation and growth: Causality and causes. Journal of Monetary Economics, 46, 31-77.

Maudos, J., \& Fernández, J. (2006). Desarrollo financiero, dependencia financiera y crecimiento económico sectorial: Nueva evidencia internacional. Papeles de Economía Española, 110, 35-49.

Rajan, R., \& Zingales, L. (1998). Financial dependence and growth. American Economic Review, 88, 559-587.

Shleifer, A., \& Wolfenzon, D. (2002). Investor protection and equity markets. Journal of Finance Economics, 66, 3-27.

Wurgler, J. (2000). Financial markets and the allocation of capital. Journal of Financial Economics, 58, 187-214. 